\title{
MAGNETIC TECHNIQUES FOR ESTIMATING ELASTIC AND PLASTIC STRAINS IN STEELS UNDER CYCLIC LOADING
}

\author{
E. S. Gorkunov, R. A. Savrai*, A. V. Makarov, S. M. Zadvorkin \\ Institute of Engineering Science, Ural Branch of the Russian Academy of Sciences, 34 Komsomolskaya st., \\ Ekaterinburg, Russian Federation \\ *Corresponding author. E-mail: ras@imach.uran.ru; address for correspondence: ul. Komsomolskaya 34, Ekaterinburg, \\ Russian Federation. Tel.: + 7 (343) 375-35-99; fax: 374-53-30
}

The paper studies the effect of high-cycle fatigue loading (elastic deformation) of highcarbon steel $(1.03 \mathrm{wt} \% \mathrm{C})$ on the behavior of the tangential component of the magnetic induction vector of a specimen in the residual magnetization state. It has been found that the magnetic measurement technique allows both structural changes and cracks resulting from the fatigue degradation of high-carbon pearlitic steel to be recorded. The effect of cyclic loading in the low-cycle fatigue region (plastic deformation) on the variations in the coercive force and residual magnetic induction of annealed medium-carbon steel $(0.45 \mathrm{wt} \% \mathrm{C})$ for the major and minor magnetic hysteresis loops has also been studied. The sensitivity of the magnetic characteristics to both large and small plastic strains accumulated during cyclic loading has been established.

Keywords: magnetic method, carbon steels, high- and low-cycle fatigue loading, fatigue degradation, accumulated plastic deformation.

\section{References}

1. Gorkunov E.S., Novikov V.N., Nichipuruk A.P., Nassonov V.V., Kadrov A.V., Tatlybaeva I. N. Resistance of residual magnetization of heat-treated steel products of elastic. The Soviet Journal of Nondestructive Testing, 1991, no. 2, pp. 138-145.

2. Gloria N.B.S., Areiza M.C.L., Miranda I.V.J., Rebello J.M.A. Development of a magnetic sensor for detection and sizing of internal pipeline corrosion defects. NDT\&E International, 2009, vol. 42, no. 8, pp. 669-677.

3. Shah M.B., Bose M.S.C. Magnetic NDT technique to evaluate fatigue damage. Physica status solidi (a), 1984, vol. 86, no. 1, pp. 275-281.

4. Babich V.K., Pirogov V.A. On the nature of the variation in the coercive force of annealed carbon steels under deformation. FMM, 1969, vol. 28, iss. 3, pp. 447-453. (In Russian).

5. Gorkunov E.S., Smirnov S.V., Rodionova S.S. Effect of plastic strain under hydrostatic pressure on the damage and magnetic characteristics of low-carbon steel 3sp. Fizicheskaya mezomekhanika, 2003, vol. 6, no. 5, pp. 101-108. (In Russian).

6. Makarov A.V., Savray R.A., Schastlivtsev V.M., Tabatchikova T.I., Egorova L.Yu. Mechanical properties and peculiarities of the fracture of high-carbon steel with various pearlitic structures under static tension. FMM, 2007, vol. 104, no. 5, pp. 542-555. (In Russian).

7. Makarov A.V., Savray R.A., Schastlivtsev V.M., Tabatchikova T.I., Yakovleva I.L., Egorova L.Yu. Structural peculiarities of the behavior of high-carbon pearlitic steel under cyclic loading. FMM, 2011, vol. 111, no. 1, pp. 97-111. (In Russian).

8. Mikheev M.N., Gorkunov E.S. Magnitnye metody strukturnogo analiza i nerazrushayuschego kontrolya [Magnetic Methods of Structural Analysis and Nondestructive Testing]. Moscow, Nauka Publ., 1993. 252 p. (In Russian).

9. Jiles D.C. The effect of compressive plastic deformation of AISI 4130 steels with various mikrostruktures. J. Phys. D. Appl. Phys, 1998, no. 21, pp. 1196-1204.

10. Kuleev V.G., Tsarkova T.P., Nichipuruk A.P. Specific features of the behavior of the coercive force in low-carbon plastically deformed steels. Russian Journal of Nondestructive Testing, 2005, vol. 41, no. 5, pp. 285-295. DOI: 10.1007/s11181-005-0168-8. 
11. Kuleev V.G., Tsarkova T.P., Nichipuruk A.P. Effect of tensile plastic deformations on the residual magnetization and initial permeability of low-carbon steels. Russian Journal of Nondestructive Testing, 2006, vol. 42, no. 4, pp. 261-271. DOI: 10.1134/S1061830906040073. 
УДК 620.179 .14

\title{
МАГНИТНЫЕ МЕТОДЫ ОЦЕНКИ УПРУГОЙ И ПЛАСТИЧЕСКОЙ ДЕФОРМАЦИИ ПРИ ЦИКЛИЧЕСКОМ НАГРУЖЕНИИ СТАЛЕЙ
}

\author{
Э. С. Горкунов, Р. А. Саврай*, А. В. Макаров, С. М. Задворкин \\ Федеральное государственное бюджетное учреждение науки Институт машиноведения Уральского отделе- \\ ния Российской академии наук, ул. Комсомольская, 34, Екатеринбург, Российская Федераџия \\ *Ответственный автор. Электронная почта: ras@imach.uran.ru; адрес для переписки: ул. Комсомольская, 34, \\ Екатеринбург, Российская Федерация. Телефон: +7 (343) 375-35-99; факс: 374-53-30
}

Исследовано влияние многоциклового усталостного нагружения (упругое деформирование) высокоуглеродистой (1,03 мас.\% С) стали на характер изменения тангенциальной составляющей вектора магнитной индукции образца в остаточно намагниченном состоянии. Установлено, что используемая методика магнитных измерений позволяет зарегистрировать как структурные изменения, так и трещины, появляющиеся вследствие усталостной деградации высокоуглеродистой перлитной стали. Исследовано также влияние циклического нагружения при малоцикловой усталости (упруго-пластическое деформирование) отожженной среднеуглеродистой $(0,45$ мас.\% С) стали на изменение коэрцитивной силы и остаточной магнитной индукции для предельной петли и для частных петель магнитного гистерезиса. Установлена чувствительность рассматриваемых магнитных характеристик к величине пластической деформации, накопленной при циклическом нагружении, в области как больших, так и малых пластических деформаций.

Ключевые слова: магнитный метод, углеродистые стали, много- и малочикловое усталостное нагружение, усталостная деградаџия, накопленная пластическая деформаџия.

\section{1. Введение}

В большинстве машин и конструкций детали работают в условиях циклически изменяющихся нагрузок и с различным уровнем напряжений в циклах. При этом уровень напряжений на разных режимах может колебаться в широких пределах и приводить к возникновению в деталях как упругих, так и пластических деформаций. Это существенно затрудняет изучение сопротивления усталости, прогнозирование долговечности и определение остаточного ресурса, требует большого объема экспериментального материала и проведения натурных испытаний. Необходимо использование таких методов, которые не сводились бы только к накоплению экспериментальных данных, а позволяли приблизиться к пониманию физических основ явлений усталости. В этой связи перспективно применение неразрушающих методов контроля, в частности, магнитных методов.

В процессе усталостного нагружения многократно повторяющаяся упругая деформация приводит к структурным изменениям и накопленной поврежденности, оказывающим влияние на магнитные свойства образца. Для обнаружения такой усталостной поврежденности перспективными являются методы магнитного контроля изделий, находящихся в остаточно намагниченном состоянии. Контроль проводят с помощью высокочувствительных датчиков, которые позволяют проводить локальные измерения магнитных полей рассеяния, в том числе на дефектах $[1,2]$.

Среди магнитных характеристик, используемых для оценки физико-механических свойств материала при пластическом деформировании, можно выделить коэрцитивную силу и остаточную индукции [3], на которые оказывают влияние изменение плотности дислокаций и появление нарушений сплошности (рыхлот, микротрещин и пор) [3-5]. В этой связи, изменение магнитных свойств и структуры при пластической деформации целесообразно 
разбить на три этапа: 1) изменение при малых деформациях; 2) при средних; 3) после больших деформаций [4].

Таким образом, цель настоящей работы - исследование влияния циклического нагружения: 1) высокоуглеродистой (1,03 мас. \% С) перлитной стали при многоцикловой усталости (упруго-пластическое деформирование) на характер изменения тангенциальной составляющей вектора магнитной индукции образца в остаточно намагниченном состоянии; 2) отожженной среднеуглеродистой $(0,45$ мас. \% C) стали при малоцикловой усталости (пластическое деформирование) на характер изменения коэрцитивной силы и остаточной магнитной индукции предельной и частных петель магнитного гистерезиса.

Настоящая работа носит обзорный характер и представляет исследования авторов в области магнитных методов оценки степени деградации сталей при циклическом нагружении.

\section{2. Материал и методика эксперимента}

Исследовали высокоуглеродистую (в мас. \%: 1,03 C; 0,072 Cr; 0,056 Ni; 0,27 Mn; 0,059 Si; 0,072 Cu; 0,023 P; 0,016 S; остальное $\mathrm{Fe}$ ) и среднеуглеродистую (в мас. \%: 0,45 C; 0,15 Cr; 0,15 Ni; 0,66 Mn; 0,33 Si; 0,16 Cu; 0,018 P; 0,028 S; остальное Fe) стали промышленной плавки. Структуру тонкопластинчатого перлита в высокоуглеродистой стали получали путем изотермической выдержки предварительно нагретых до $1050{ }^{\circ} \mathrm{C}$ (выдержка при температуре $1050{ }^{\circ} \mathrm{C}$ составила 15 мин) заготовок при температуре $500{ }^{\circ} \mathrm{C}$ в течение 5 мин в соляной ванне (с последующим охлаждением в воде). Затем образцы отжигали в соляной ванне при температуре $650{ }^{\circ} \mathrm{C}$ в течение 10 мин. Указанный кратковременный отжиг позволяет устранить повышенную хрупкость перлита, формирующегося в стали У10 при температуре изотермического распада $500{ }^{\circ} \mathrm{C}$, и сохранить при этом морфологию тонкопластинчатого перлита [6]. Среднеуглеродистую сталь подвергали отжигу при температуре $800{ }^{\circ} \mathrm{C}$ в течение 8 часов с последующим охлаждением с печью. Данную обработку проводили с целью получения равновесной структуры с минимальным количеством дефектов и уровнем остаточных напряжений.

Механические испытания проводили на сервогидравлической испытательной установке Instron 8801. Циклическое нагружение образцов из высокоуглеродистой перлитной стали проводили с контролируемой величиной напряжения $\Delta \sigma=2 \sigma_{\mathrm{a}}=0,65 \sigma_{0,2}\left(\sigma_{\mathrm{a}}-\right.$ амплитуда напряжений цикла; $\sigma_{0,2}-$ условный предел текучести при статическом растяжении), коэффициентом асимметрии цикла $R_{\sigma}=0$ (знакопостоянное отнулевое растяжение), изменением напряжения цикла по синусоидальному закону, частотой нагружения 10 Гц. Образец с сечением рабочей части $6 \times 5$ мм и рабочей длиной 25 мм нагружали поэтапно с числом циклов нагружения $\mathrm{N}=20000 ; 60000 ; 100000 ; 160000$ без разрушения образцов. Дополнительно один образец был доведен до разрушения, при этом число циклов составило Np = 195980 .

Циклическое нагружение образцов с диаметром рабочей части 5 мм и рабочей длиной 25 мм из отожженной среднеуглеродистой стали проводили с контролируемой величиной общей деформации $\varepsilon_{\text {общ }}=2 \varepsilon_{\mathrm{a}}=\varepsilon_{\text {упр }}+\varepsilon_{\text {пл }}=0,0076$ ( $\varepsilon_{\mathrm{a}}-$ амплитуда полной деформации цикла; $\varepsilon_{\text {упр }}$ - амплитуда упругой деформации цикла; $\varepsilon_{\text {пл }}$ - амплитуда пластической деформации цикла), коэффициентом асимметрии цикла $\mathrm{R}_{\varepsilon}=0$ (знакопостоянное отнулевое растяжение), изменением амплитуды деформации цикла по пилообразному закону, частотой нагружения 0,5 Гц. При этом испытания осуществляли таким образом, чтобы коэффициенты асимметрии цикла как по деформации, так и по напряжению оставались равны нулю на протяжении всего процесса нагружения $\left(\mathrm{R}_{\sigma}=\mathrm{R}_{\varepsilon}=0\right)$. Испытывали образцы с количеством циклов нагружения $N=5,10,50,200$ и 400 без разрушения образцов.

Магнитные измерения проводили после циклических испытаний в разгруженном состоянии. Магнитные измерения тангенциальной составляющей вектора индукции $\mathrm{B}_{\mathrm{t}}$ высокоуглеродистой перлитной стали проводили феррозондовым датчиком, установленным в ска- 
нирующем устройстве, позволяющем сканировать поверхность образца вдоль оси с постоянной скоростью 2 мм/с и выдерживать зазор 0,3 мм между магниточувствительным элементом и образцом. Образец намагничивали продольно в направлении оси образца с использованием намагничивающего устройства на высокоэнергоемких постоянных магнитах $\mathrm{Nd}-\mathrm{Fe}-\mathrm{B}$. Намагниченный образец устанавливали на столе сканирующего устройства и перемещали феррозондовый преобразователь магнитометра Foerster Magnetoscop 1.069 вдоль поверхности образца. Измерения коэрцитивной силы и остаточной магнитной индукции отожженной среднеуглеродистой стали осуществляли с использованием магнитоизмерительного комплекса Remagraph C-500 на предельной (Hmax=60 кA/м) и частных (при максимальной магнитной индукции цикла гистерезиса $b \max =1 ; 0,4 ; 0,1$ и 0,05 Тл) петлях магнитного гистерезиса.

Структуру образцов после циклического растяжения изучали на электронном сканирующем микроскопе Tescan Vega II XMU. Изображения трещины получали на электронном сканирующем микроскопе высокого разрешения Tescan Mira 3 LMU с автоэмиссионным катодом Шоттки высокой яркости.

\section{3. Экспериментальные результаты и их обсуждение}

На рис. $1 a$ представлена электронная микрофотография структуры высокоуглеродистой перлитной стали, подвергнутой диффузионному распаду при температуре изотермической выдержки $500{ }^{\circ} \mathrm{C}$, а также дополнительному отжигу при $650{ }^{\circ} \mathrm{C}$ в течение 10 мин. При температуре изотермического превращения $500{ }^{\circ} \mathrm{C}$ в стали формируется структура тонкопластинчатого перлита с межпластинчатым расстоянием $\lambda=0,08-0,14$ мкм и размерами колоний 5-15 мкм [6]. Кратковременный (10 мин) отжиг при $650{ }^{\circ} \mathrm{C}$ не приводит к изменениям в морфологии карбидной фазы: отсутствует сфероидизация и коалесценция цементита (см. рис. 1a).

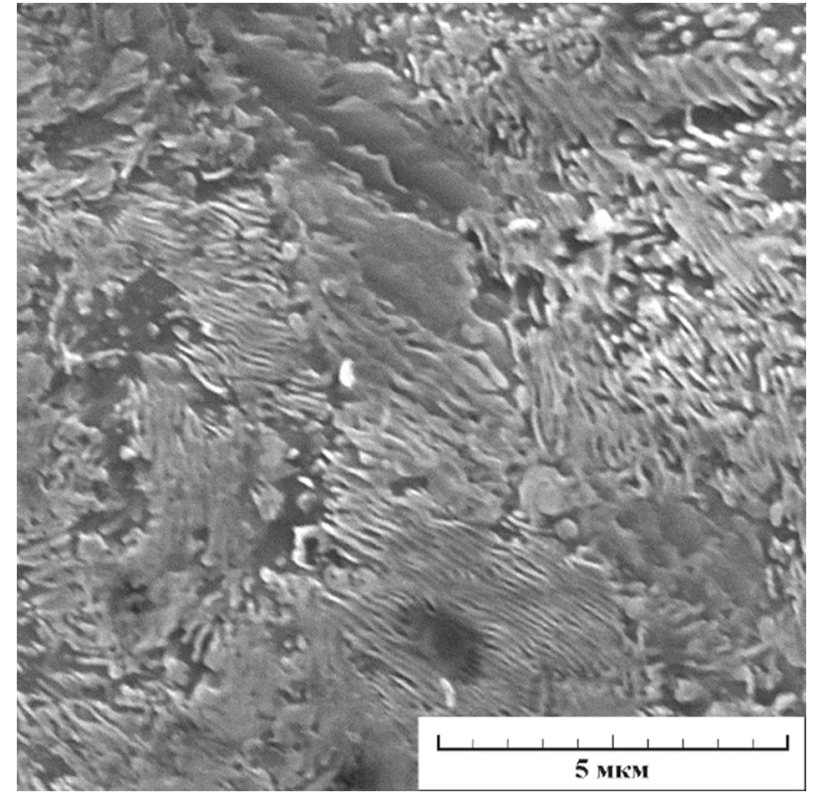

$a$

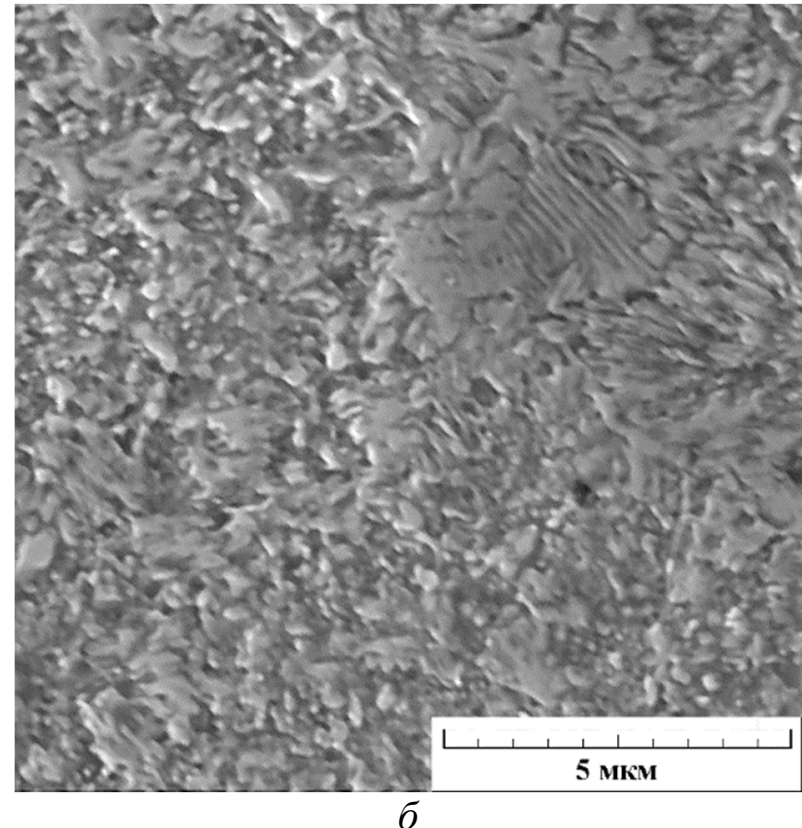

Рис. 1. Электронные микрофотографии (РЭМ) высокоуглеродистой перлитной стали со структурой тонкопластинчатого перлита после кратковременного отжига: $a-$ в исходном состоянии; $\sigma$ - после усталостного разрушения

Рассмотрим влияние многоциклового усталостного нагружения (упругое деформирование) высокоуглеродистой перлитной стали на изменение тангенциальной составляющей вектора индукции $\mathrm{B}_{\mathrm{t}}$. Как следует из рис. 2, усталостные испытания сопровождаются появлением неоднородности распределения тангенциальной составляющей вектора магнитной индукции в остаточно намагниченном состоянии образца по его длине, заметной уже при 
$N=60000$. При усталостном нагружении с числом циклов $N=100000$ наблюдается заметный рост величины $\mathrm{B}_{\mathrm{t}}$. Это может быть обусловлено структурными изменениями, протекающими в перлитной стали при усталостном нагружении, в частности, сфероидизацией цементитных пластин (см. рис. 1б). Сфероидизация дисперсных цементитных пластин при циклическом растяжении в условиях многоцикловой усталости обусловлена совместным действием упругих растягивающих напряжений, микропластической деформации и эффектов локального нагрева, ускоряющих диффузию атомов железа и углерода [7].
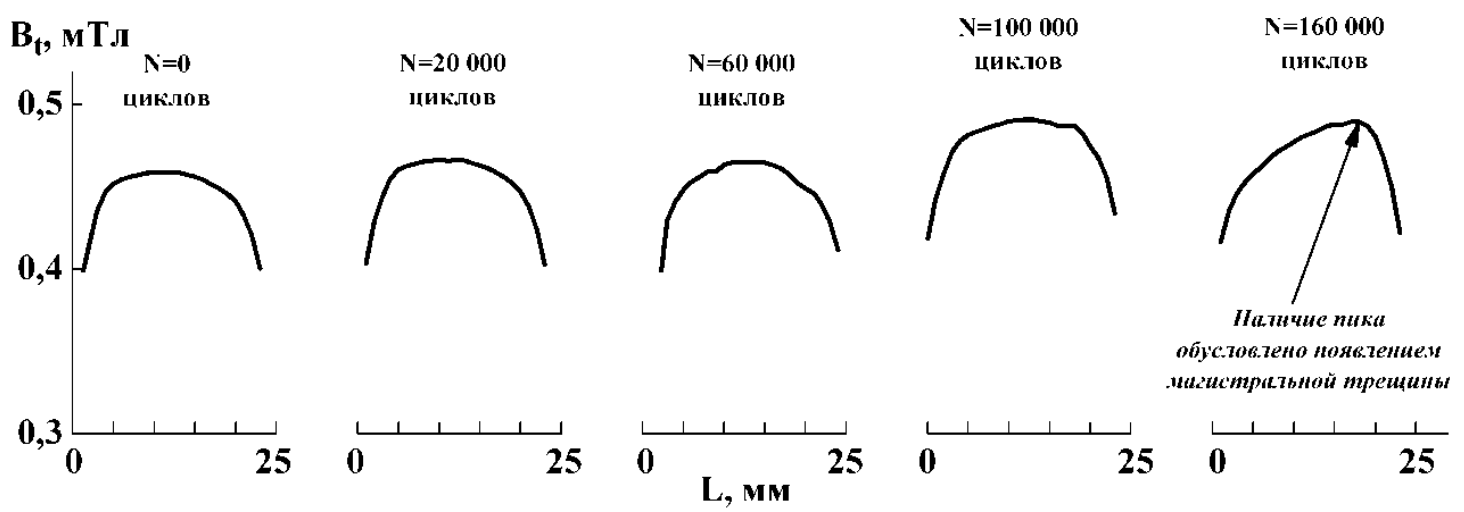

Рис. 2. Распределение тангенциальной составляющей магнитной индукции $\mathrm{B}_{\mathrm{t}}$ по рабочей зоне образца в остаточно намагниченном состоянии до нагружения $(\mathrm{N}=0)$ и после нагружения с заданным числом циклов. Результаты измерений приведены для той стороны образца, на которой была обнаружена магистральная усталостная трещина

При числе циклов нагружения $N=160000$ на графике распределения тангенциальной составляющей вектора магнитной индукции $\mathrm{B}_{\mathrm{t}}$ наблюдается ярко выраженный пик (см. рис. 2). Его наличие обусловлено появлением магистральной усталостной трещины, которая зародилась на поверхности образца на имеющемся концентраторе напряжений (рис. 3). Отметим, что ширина раскрытия усталостной трещины составляет менее 1 мкм, что свидетельствует о возможности неразрушающего контроля усталостной деградации сталей при многоцикловом усталостном нагружении (упругое деформирование).

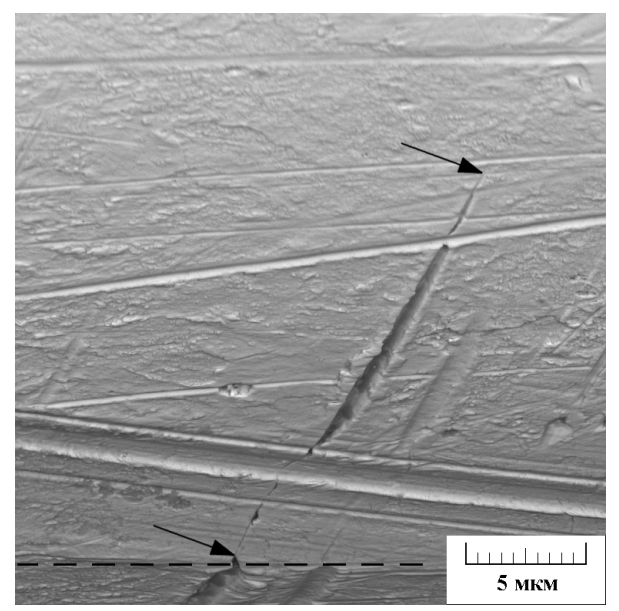

Рис. 3. Электронная микрофотография (РЭМ) поверхности образца (после нагружения с числом циклов $\mathrm{N}=160000)$. Стрелками обозначена усталостная трещина; пунктирной линией - край образца, параллельный оси нагружения

Рассмотрим влияние циклического нагружения при малоцикловой усталости (упругопластическое деформирование) отожженной среднеуглеродистой стали на изменение ее магнитных характеристик. 
Материал в исходном отожженном состоянии, микроструктура которого приведена на рис. 4, характеризуется минимальными значениями коэрцитивной силы (таблица).

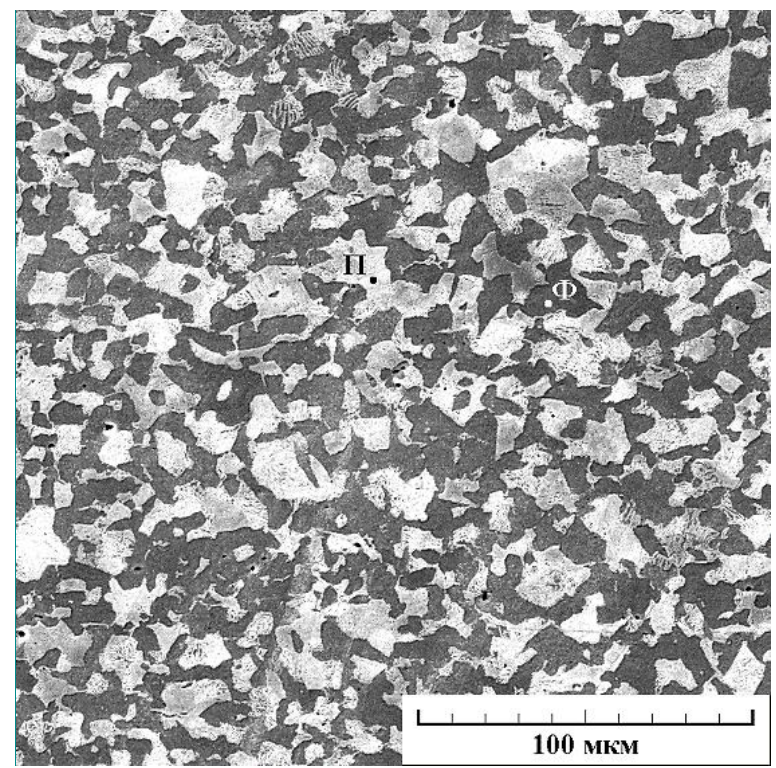

Рис. 4. Электронная микрофотография (РЭМ) среднеуглеродистой стали в исходном отожженном состоянии: $\Phi$ - феррит, П - перлит

Таблица - Значения коэрцитивной силы и остаточной магнитной индукции среднеуглеродистой стали в исходном отожженном состоянии $\left(\mathrm{N}=0, \varepsilon_{\Sigma}=0\right)$

\begin{tabular}{|l|l|l|l|l|l|l|l|l|l|}
\hline \multicolumn{2}{|c|}{$\mathrm{b}_{\max }=0,05$ Тл } & \multicolumn{2}{|c|}{$\mathrm{b}_{\max }=0,1$ Тл } & \multicolumn{2}{|c|}{$\mathrm{b}_{\max }=0,4$ Тл } & \multicolumn{2}{|c|}{$\mathrm{b}_{\max }=1$ Тл } & \multicolumn{2}{c|}{$\begin{array}{c}\mathrm{H}=60 \text { кА/м } \\
\text { (предельная } \\
\text { петля) }\end{array}$} \\
\hline $\mathrm{h}_{\mathrm{C}}, \mathrm{A} / \mathrm{M}$ & $\mathrm{b}_{\mathrm{r}}$, Тл & $\mathrm{h}_{\mathrm{C}}, \mathrm{A} / \mathrm{M}$ & $\mathrm{b}_{\mathrm{r}}, \mathrm{Tл}$ & $\mathrm{h}_{\mathrm{C}}, \mathrm{A} / \mathrm{M}$ & $\mathrm{b}_{\mathrm{r}}$, Тл & $\mathrm{h}_{\mathrm{C}}, \mathrm{A} / \mathrm{M}$ & $\mathrm{b}_{\mathrm{r}}$, Тл & $\mathrm{H}_{\mathrm{C}}, \mathrm{A} / \mathrm{M}$ & $\mathrm{B}_{\mathrm{r}}$, Тл \\
\hline 15,55 & 0,017 & 31,8 & 0,043 & 99,7 & 0,3 & 146,2 & 0,766 & 194,5 & 1,159 \\
\hline
\end{tabular}

В процессе усталостного нагружения наблюдается рост значений коэрцитивной силы как для предельной, так и для частных петель магнитного гистерезиса (рис. 5a, б). Отметим существенное различие в изменении коэрцитивной силы в слабых и сильных полях. В слабых полях (до 0,1 Тл включительно, когда максимальное поле петли гистерезиса $\mathrm{h}_{\max }<\mathrm{H}_{c}$ ) коэрцитивная сила частных циклов непрерывно возрастает на протяжении всего процесса деформирования, при этом наблюдается ее резкое увеличение на начальном этапе деформирования, которое с увеличением степени деформации сменяется более плавным ростом. Это обусловлено повышением общей плотности дефектов, что вызывает рост градиентов микронапряжений, увеличение значений критических полей взаимодействия доменных границ с дефектами и, соответственно, затруднение процессов перемагничивания $[8,9]$. Наблюдаемый рост коэрцитивной силы может быть обусловлен не только увеличением плотности дефектов кристаллического строения при циклическом растяжении, но и появлением значительных остаточных сжимающих напряжений при разгрузке пластически деформированных образцов $[10,11]$.

При перемагничивании в более сильных полях при суммарной пластической деформации 7-10 \% наблюдается стабилизация значений коэрцитивной силы вплоть до величины деформации 15-17\%. Такая стабилизация может быть связана с формированием ячеистой дислокационной структуры. В этом случае уменьшается вероятность необратимых смещений доменных границ, т.е. уменьшается роль необратимых процессов перемагничивания. Дальнейшая деформация вновь сопровождается ростом значений коэрцитивной силы, который 
можно объяснить появлением микропор, количество и размер которых возрастают вплоть до разрушения. Микропоры, являясь источниками магнитных полей рассеяния, в соответствии с «теорией включений» [8] будут препятствовать процессам перемагничивания.
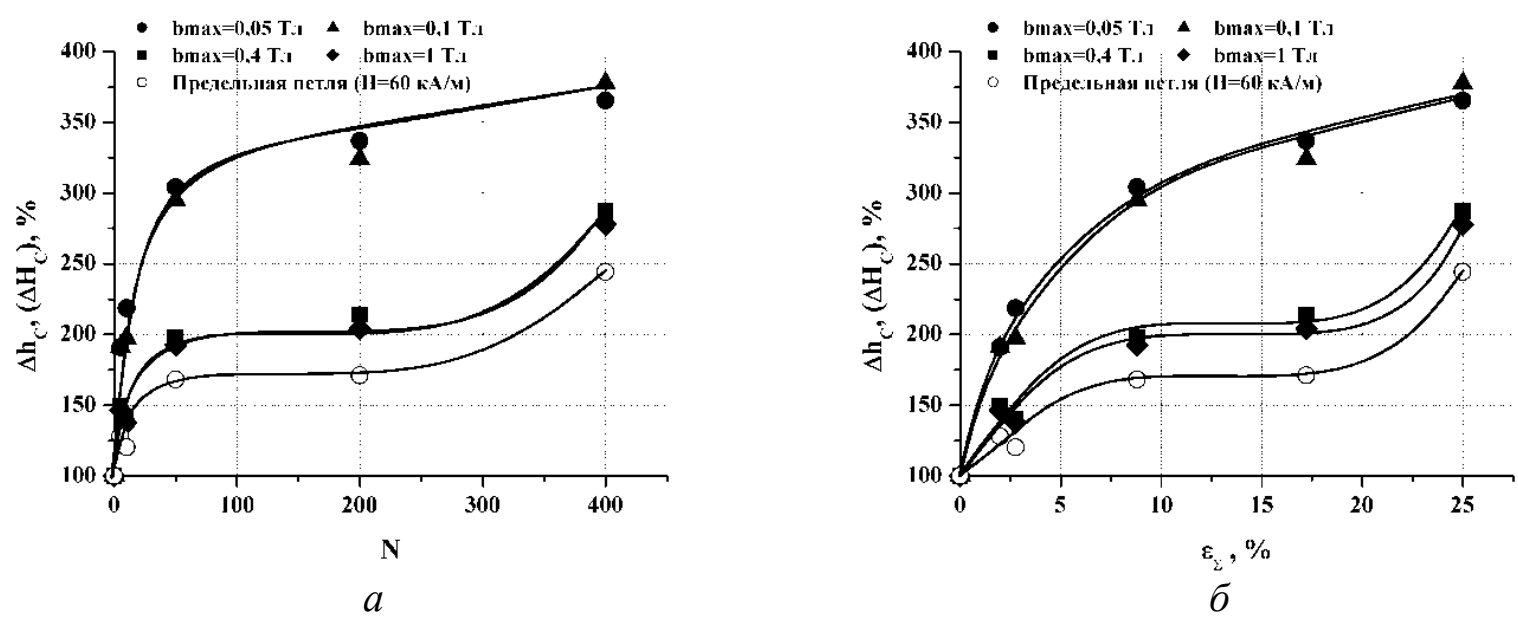

Рис. 5. Зависимость относительного изменения коэрцитивной силы от числа циклов нагружения (a) и величины накопленной пластической деформации (б) образцов из среднеуглеродистой стали. За 100 \% взяты значения коэрцитивной силы в исходном отожженном состоянии (таблица)

В процессе деформирования на начальном этапе при суммарной пластической деформации до 7-10 \% наблюдаются снижение значений остаточной индукции для предельной петли и для частных петель при максимальной магнитной индукции цикла гистерезиса $\mathrm{b}_{\max }=1$ и 0,4 Тл и (при суммарной пластической деформации до $2-3 \%$ ) рост значений остаточной индукции для частных петель при максимальной магнитной индукции цикла гистерезиса 0,1 и 0,05 Тл (рис. $6 a, 6$ ).
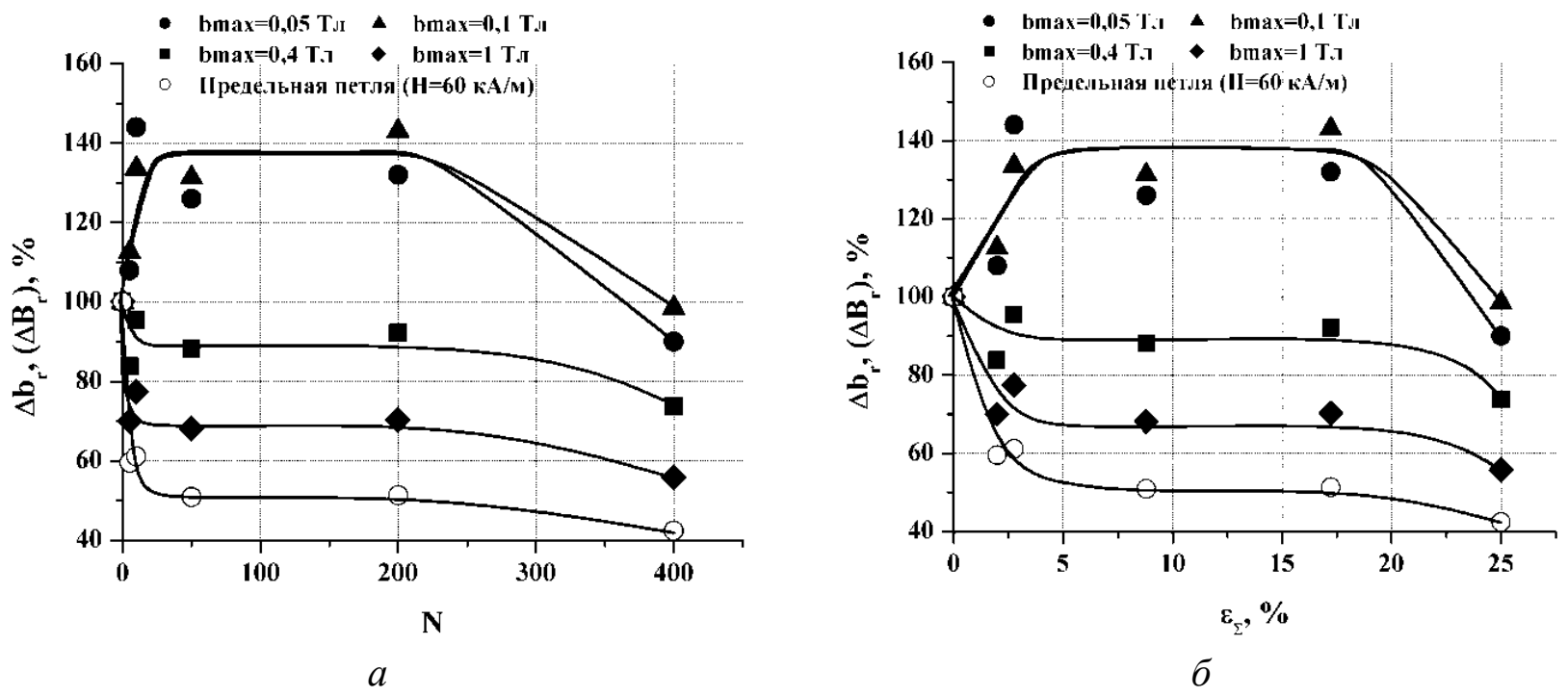

Рис. 6. Зависимость относительного изменения остаточной индукции от числа циклов нагружения $(a)$ и величины накопленной пластической деформации (б) образцов из среднеуглеродистой стали. За 100 \% взяты значения остаточной индукции в исходном отожженном состоянии (таблица)

Таким образом, как и в случае коэрцитивной силы, изменение остаточной индукции в слабых и сильных полях также различно. С одной стороны, участки, имеющие значительные 
локальные микронапряжения (в частности дислокации), являются местом легкого образования зародышей перемагничивания [8]. Это отражается в наблюдаемом снижении остаточной индукции в сильных полях. С другой стороны, перераспределение дислокаций приводит к появлению областей с менее дефектной структурой. При намагничивании образца в слабых полях смещения доменных границ невелики и, по-видимому, не превышают размеры этих областей. Поэтому значения остаточной индукции в слабых полях возрастают до завершения формирования ячеистой дислокационной структуры во всем объеме материала. После этого наблюдается стабилизация значений остаточной индукции вплоть до величины деформации 15-17 \%. Дальнейшая деформация сопровождается снижением значений остаточной индукции независимо от величины поля, что можно объяснить появлением микропор. На макродефектах, в частности трещинах и порах, возникают магнитные поля рассеяния [8], которые направлены противоположно намагничивающему полю, что, в итоге, приводит к снижению значений остаточной индукции.

\section{4. Заключение}

Установлено, что многоцикловое усталостное нагружение (упругое деформирование) образцов из высокоуглеродистой (1,03 мас. \% С) стали до появления усталостной трещины приводит к увеличению тангенциальной составляющей вектора магнитной индукции образца в остаточно намагниченном состоянии и появлению неоднородности ее распределения по длине образца. Это обусловлено структурными изменениями (сфероидизацией цементинтых пластин), протекающими в высокоуглеродистой перлитной стали при многоцикловом усталостном нагружении. При появлении магистральной усталостной трещины на графике распределения тангенциальной составляющей вектора магнитной индукции наблюдается ярко выраженный пик. Показана возможность контроля усталостной деградации сталей при циклическом нагружении в области многоцикловой усталости.

Получены зависимости, описывающие изменение коэрцитивной силы, остаточной магнитной индукции для предельной петли и для частных петель магнитного гистерезиса от числа циклов нагружения (величины накопленной пластической деформации) при циклическом нагружении в области малоцикловой усталости (упруго-пластическое деформирование) образцов из отожженной среднеуглеродистой $(0,45$ мас. \% С) стали, которые свидетельствуют о чувствительности рассматриваемых характеристик к величине пластической деформации в области как больших, так и малых деформаций. Показана возможность контроля пластической деформации, накопленной при циклическом нагружении, по значениям магнитных параметров.

Работа выполнена при поддержке проекта № 12-П-1-1027 по программе Президиума PAH № 25.

Электронная сканирующая микроскопия и магнитные измерения выполнены в ЦКП «Пластометрия» ИМАШ УрО РАН.

\section{Литература}

1. Resistance of residual magnetization of heat-treated steel products of elastic deformations / E. S. Gorkunov, V. N. Novikov, A. P. Nichipuruk, V. V. Nassonov, A. V. Kadrov, I. N. Tatlybaeva // The Soviet Journal of Nondestructive Testing. - 1991. - № 2. - P. 138-145.

2. Development of a magnetic sensor for detection and sizing of internal pipeline corrosion defects / N. B. S. Gloria, M. C. L. Areiza, I. V. J. Miranda, J. M. A. Rebello // NDT\&E International. - 2009. - Vol. 42, № 8. - P. 669-677.

3. Shah M. B., Bose M. S. C. Magnetic NDT technique to evaluate fatigue damage // Physica status solidi (a). - 1984. - Vol. 86, № 1. - P. 275-281. 
4. Бабич В. К., Пирогов В. А. О природе изменения коэрцитивной силы при деформации отожженных углеродистых сталей // ФММ. - 1969. - Т. 28, вып. 3. - С. 447-453.

5. Горкунов Э. С., Смирнов С. В., Родионова С. С. Влияние пластической деформации при гидростатическом давлении на поврежденность и магнитные характеристики низкоуглеродистой стали 3сп // Физическая мезомеханика. - 2003. - Т. 6, № 5. - С. 101-108.

6. Механические свойства и особенности разрушения при статическом растяжении высокоуглеродистой стали с перлитными структурами различного типа / А. В. Макаров, Р. А. Саврай, В. М. Счастливцев, Т. И. Табатчикова, Л. Ю. Егорова // ФММ. - 2007. - Т. 104, № 5. - C. 542-555.

7. Структурные особенности поведения высокоуглеродистой перлитной стали при циклическом нагружении / А. В. Макаров Р. А. Саврай, В. М. Счастливцев, Т. И. Табатчикова, И. Л. Яковлева, Л. Ю. Егорова // ФММ. - 2011. - Т. 111, № 1. - С. 97-111.

8. Михеев М. Н., Горкунов Э. С. Магнитные методы структурного анализа и неразрушающего контроля. - М. : Наука, 1993. - 252 с.

9. Jiles D. C. The effect of compressive plastic deformation of AISI 4130 steels with various mikrostruktures // J. Phys. D. Appl. Phys. - 1998. - № 21. - P. 1196-1204.

10. Kuleev V. G., Tsarkova T. P., Nichipuruk A. P. Specific features of the behavior of the coercive force in low-carbon plastically deformed steels // Russian Journal Of Nondestructive Testing. - 2005. - Vol. 41, no. 5. - P. 285-295. DOI: 10.1007/s11181-005-0168-8.

11. Kuleev V. G., Tsarkova T. P., Nichipuruk A. P. Effect of tensile plastic deformations on the residual magnetization and initial permeability of low-carbon steels // Russian Journal Of Nondestructive Testing. - 2006. - Vol. 42, no. 4. - P. 261-271. DOI: 10.1134/S1061830906040073. 